Corresponding Author: Inam Jasim Lafta; email: ijlafta@gmail.com

Received 21 February 2019

Accepted 12 May 2019

Published 28 June 2019

Production and Hosting by Knowledge E

(c) Inam Jasim Lafta and Naer Abdulbari Madlood

Alkaabawi. This article is distributed under the terms of the Creative Commons

Attribution License, which permits unrestricted use and redistribution provided that the original author and source are credited.

Editor-in-Chief:

Prof. Mohammad A. M. Ibnouf

\section{Positive and Negative Effects of the Commensal Bacteria on Carcinogenesis}

\section{Inam Jasim Lafta ${ }^{1}$ and Naer Abdulbari Madlood Alkaabawi ${ }^{2}$}

${ }^{1}$ Zoonotic Diseases Unit, College of Veterinary Medicine, University of Baghdad, Baghdad, Iraq ${ }^{2}$ Department of Microbiology, College of Veterinary Medicine, University of Al-Muthana, AlMuthana, Iraq

\section{Abstract}

Background: Cancer is a lethal disease that results from a multifactorial process. Progression into carcinogenesis and an abnormal cell proliferation can occur due to the micro and macro environment as well as genetic mutations and modifications. In this review, cancer and the microbiota - mainly bacteria that inhabit the tumour tissue - have been discussed. The positive and negative impacts of the commensal bacteria on tumours being protective or carcinogenic agents, respectively, and their strategies have also been described.

Methods: Related published articles written in English language were searched from Google Scholar, PubMed, Mendeley suggestions, as well as Google search using a combination of the keywords 'Microbiota, commensal bacteria, cancer, tumor'. Relevant literature published between the years 1979 and 2018 were included in this review.

Results: The complicated nature of cancer as well as the role that might be played by the commensal bacteria in affected tissues have been the focus of the recent studies. The symbiotic relationships between the microbiota and the host have been shown to confer benefits to the last. By contrast, the microbiota has been suggested to upgrade cancer by modifying the balance of host cell proliferation and death, by provoking chronic inflammation, and by eliciting uncontrolled innate and adaptive immunity. In this context, aerobic and anaerobic bacteria have been isolated from various tumor samples.

Conclusions: It can be concluded that commensal microbiota plays an important role in the prevention of diseases including cancer. Inversely, microbiota alterations (dysbiosis) have been found to interrupt that symbiotic correlation between the host and the inhabitant microbiota probably leading to cancer.

Recommendations: The correlation between the commensal microbiome, antibiotics uptake and cancer occurrence need to be investigated exclusively. Moreover, increased attention must be paid to evaluating the effects of these microorganisms on the currently used anticancer agents, and the role that might be played by commensal bacteria on tumor progression or tumor regression.

Keywords: microbiota, commensal bacteria, heath, cancer 


\section{Introduction}

Cancer is the second leading cause of death in both developed and developing countries. A normal cell must undergo many molecular changes to be transformed into a cancer cell. Hence, the probability that such events occur in an individual cell is rising with age [1]. Malignant transformation of cells has been attributed to many factors, including genetic, life style, hormones, proteases, cytokines along with immune and stromal cells [2, 3]. Recently, increased incidence of cancer cases has been reported across the world countries including Iraq.

Cancer has been treated by numerous traditional therapeutic approaches, such as chemotherapy and radiotherapy, which are available for around $50 \%$ of the cancer victims [4]. Despite intensive research, no appropriate therapy for most of cancer types has been developed [5]. However, certain microorganisms have been shown to have the capability to control the cancer cell growth throughout the affected area [6]. The microorganisms that live symbiotically in the bodies of human beings have been progressively documented as vital players in health and disease [7]. The tumor-associated microbiota could play dual roles on cancer therapy. The positive effect of bacteria as anti-tumor agents includes the important functions of their toxins, enzymes, and spores against cancer development. While their negative influence on cancer might be via the interference with cancer drugs preventing them from affecting cancer, adding to the impact of dysbiosis (microbial perturbation) on enhancing carcinogenesis [8].

Many studies have focused on the use of certain bacteria as anti-cancers, such as the findings of [9-11]. Many bacteria are actively mobile and move away from the vasculature, penetrate deeply, and accumulate in tumor tissue. This makes therapy based on bacteria to achieve sufficient tissue penetration, which cannot be accomplished with other treatments, including radiation and chemotherapy [12]. Although possible biosafety and other harmful impacts, for example, underlying bacterial toxicity, decreased targeting efficiency, genomic instability, and complex interactions with other treatments are the main limitations of using bacteria to target tumors $[8,13,14]$. Altogether, because of the important positive and negative roles that might be played by commensal bacteria in tumor tissues, and because no more studies are available concerning the correlations of microbiota with cancer. Therefore, this subject has been taken into account to review the microbiome-inhabiting tumours, focusing on the existing bacteria and shedding light on the effects and strategies of commensal bacteria on tumours as protective against or enhancer for carcinogenesis. 


\section{Methods}

Related published articles written in English language were searched from Google Scholar, PubMed, Mendeley suggestions, as well as Google search using a combination of the keywords: 'microbiota, commensal bacteria, cancer, tumour'. Relevant literature published between the years 1979 and 2018 were included in this review.

\section{Results}

This review article included 126 references published in prestigious scientific journals. Most of the searched literature has been published recently, with some articles being published in the last three or four decades. The results of the search are shown in the below sections:

\subsection{Tumorigenesis}

Tumorigenesis is the process that originates as cells are liberated from growth controls, and the promotion takes place as the immune system is eluded, which in turn will support more mutations and increased loss of cell regulation [15]. Although genetic mutations and alterations are essential for cancer cells proliferation [16], tumour progression and ultimate invasion of the host also depends on the response of the host to inflammation and antitumor immunity [17].

Importantly, angiogenesis, which is the process of formation of new blood vessels, results when the tumor continues to multiply and becomes in need to a greater blood supply. If the tumor breaks down, succeeding invasion to the surrounding tissues occurs. Metastasis is the poorest outcome that takes place when cells separate from the tumour and seed tumours at far sites [15].

\subsection{Commensal bacteria}

Different habitats of human body, such as the gut, skin, mucosa, vagina, mouth, nose, conjunctiva, pharynx and urethra, among others are colonized by a large number of microorganisms, which are called normal microflora or the microbiota [18]. In the human body, the number of microbial cells is 10 times bigger than the number of eukaryotic cells [7]. The microbiota of each organ is different, and there is a significant and 
functionally relevant inter-individual inconsistency of microbiota, which makes them a possible determinant of diseases including cancer [19].

The words microbiota and microbiome are frequently used as synonyms, nevertheless, they express two different meanings: while microbiota signifies the whole microbes (bacteria, viruses, fungi, archaea, and protozoa) in a certain environment, the microbiome is the total genomes of a microbiota and is frequently used to express the entity of microbial traits (functions) encoded by a microbiota [20]. Among the commensal microorganisms, bacteria represent the main microbiota, which predominantly colonize skin, specially skin folds, the upper airways, mainly the nasopharynx, and some mucosal surfaces of the genital tract, although the largest numbers of bacterial cells are present in the digestive tract. Furthermore, the oral cavity, including tongue, teeth, and periodontal tissues hold increased numbers of bacteria [18, 21].

Similar to normal epithelial and mucosal surfaces of the body, tumour is also occupied by microbiome especially bacteria [22]. Interestingly, bacteria were found in $69 \%$ of various necrotic tumour specimens, which involved abdominal, pelvic, lungs, mediastinal, lymphatic, breast, head, and neck tumours. Importantly, aerobic or facultative anaerobic bacteria were isolated from $19 \%$ of specimens, anaerobes from $16 \%$, and $65 \%$ of specimens showed mixed aerobic and anaerobic bacteria. The predominant aerobic and facultative anaerobic bacteria most commonly isolated were Staphylococcus aureus, S. epidermidis, $\partial$-hemolytic streptococci, Escherichia coli, Klebsiella pneumoniae, and Pseudomonas aeruginosa. While the anaerobic bacteria included Bacteroides spp., anaerobic cocci, and Propionibacterium [23].

One of the organs extensively studied for the presence of microbiota is human breast tissue, where a varied community of bacteria were isolated, unlike what was thought that body sites are sterile. Proteobacteria were the principal phylum isolated [24], while Bacillus, Acinetobacter, Enterobacteriaceae, Pseudomonas, Staphylococcus, Propionibacterium, Comammonadaceae, Gammaproteobacteria, and Prevotella were the abundant taxa found in the breast tissue of the Canadian women. Enterobacteriaceae, Staphylococcus, Listeria welshimeri, Propionibacterium, and Pseudomonas were mainly grown from Irish samples [24]. It has been shown that the microbiome is different in normal, benign, and malignant breast tissue, and malignancy was associated with an enrichment in low abundant taxa, exemplified by the genera Lactobacillus, Fusobacterium, Atopobium, Gluconacetobacter, and Hydrogenophaga [25]. Recently, various Gram-positive and Gram-negative bacterial species have been grown aerobically from 100 benign and malignant breast tumour specimens of Iraqi patients. The most 
common isolates were S. epidermidis (50.6\%), although S. aureus, Bacillus species, $P$. fluorescence, and Enterobacteriaceae were also isolated [26].

\subsection{Effects of commensal bacteria on tumours}

\subsubsection{The protective role of commensal bacteria against diseases including cancer}

Symbiotic relationships are found between the host and microbiota; such relationship grants benefits to the host [27]. The physiological interaction that occurs between the gut microbiota, for example, and the host immune system has been shown to be necessary in many aspects. Firstly, to avoid tissue-damaging inflammatory responses directed against the commensal bacteria, including different species of Bacteroides and Clostridia in the colon and Proteobacteria and Lactobacilli in the small intestine. Secondly, in preventing the infection of pathogens, for example, Salmonella and Shigella spp. Thirdly, inhibiting the uncontrolled growth of indigenous organisms such as vancomycin-resistant enterococci and Clostridium difficile [28, 29]. And finally, the gut microbiota itself is required for an efficient mucosal repair following epithelial damage [30].

The full development of the host's immune system requires exposure to the microbiota after birth. This microbial exposure in early life has been suggested to have longlasting effects into later life [31]. Experimentally, delayed microbial colonization of germfree mice was shown to result in increased morbidity of inflammatory bowel diseases and allergic asthma [32]. Mutually, the composition and stability of the commensal microbiota depends on the local defence mechanisms of the host [33].

The oral cavity holds a large number of microorganisms that frequently form biofilms [34]. The oral microflora plays a big role in responding to the infection and modulating local immunity $[35,36]$. In the nasal cavity, the normal resident S. spp. can provide defence against pathogens. It has been observed that nasal colonization by S. aureus could be inhibited by the nasal microflora, exemplified by S. epidermidis strain that produces a serine protease or S. Iugdunensis strain that produces a thiazolidine-containing cyclic peptide $[37,38]$. Commensal bacteria colonizing the breast tissue could sustain its health by stimulating the inflammatory responses of the host. In particular, the abundance of the bacterium Sphingomonas yanoikuyae in breast tissue was associated with the healthy status of women compared to the tumorous breast tissue where spectacular decrease in the numbers of the aforementioned bacterium occurred [39]. 
A typical and abundant commensal microbiota has been shown to colonize the lungs and the vaginal mucosa, and contributes to the local immune homeostasis [40].

Skin, which is the largest organ of the body, harbours a large number of microbiota. Germ-free mice have been shown to be more vulnerable to skin infections than mice maintained under specific pathogen-free conditions [41]. The microbiota acts as a functional luminal barrier; inhibits the growth of pathogens by competing for resources, and maintains epithelial cell turnover via stimulating mucin production [7]. The microbiota inhabiting epithelial barrier surfaces, including the skin and the gastrointestinal tract, interacts with its host either directly or by means of releasing products, for example, proteins, carbohydrates, lipids, and nucleic acid. All of these products regulate local inflammation and immunity [42].

There are several mechanisms by which the commensal microbiota controls the host's immune response at different barrier surfaces. Staphylococcus epidermidis, for instance, one of the commensals of skin, has been shown to assist the immune function of the skin by reducing inflammation after injury [43], improving cutaneous T cells development, as well as stimulating the expression of host anti-microbial peptides (AMPs) such as cathelicidins and $\beta$-defensins [44-47]. Specific strains of coagulase-negative staphylococcal (CNS) spp. have been demonstrated to protect host against infectious pathogens by producing proteins that work together with endogenous host AMPs [48, 49]. Clinical studies have observed that strains of S. epidermidis, S. hominis, and other CNS that produce various AMPs were insufficient in patients of atopic dermatitis colonized with S. aureus [49]. Phenol-soluble modulins (PSMY and PSM $\delta$ ) produced by S. epidermidis have been found to selectively kill the pathogenic bacteria, for example, S. aureus and Streptococcus, group A [50]. Importantly, S. epidermidis of the skin has been shown to play a protective role against skin cancer. The molecule 6-N-hydroxyaminopurine (6HAP) produced by $S$. epidermidis has been verified by $[23,51]$ to impair tumour growth by inhibiting DNA polymerase activity.

In the gut, short-chain fatty acids (SCFAs), which are bacterial fermentation products resulting from the fermentation of dietary fibres in the colon, have been shown to influence the mucosal immunity and provoke the production of interleukin 18 (IL-18) by enterocytes $[52,53]$. Interleukin 18 supports the repair of mucosal tissue by controlling the production and availability of IL-22 [54], which in turn, prompts epithelial cell proliferation and antibacterial peptides production. Accordingly, IL-22 induces epithelial repair, and based on the degree of mucosal damage, it could be pro- or anti-carcinogenic [54-56]. Furthermore, bacterial SCFAs have been shown to regulate the size and functions of the regulatory $T$ cell (T-reg) pool. These SCFAs, for example, butyrate, 
have been demonstrated to restrain the inflammation and carcinogenesis of colon by stimulating the anti-inflammatory cytokine IL-10 production through inducing the T-reg cells expansion $[52,53,57]$. In this context, $B$. fragilis, which is a normal component of the human gut microbiota, has been found to play a role in the differentiation of IL-10producing T-reg cells by signalling through its capsular polysaccharide A [58]. Moreover, $B$. fragilis was able to protect mice from colitis induced by tri-nitrobenzene sulfonic acid and infections of Helicobacter hepaticus $[58,59]$.

\subsubsection{Commensal bacteria-inducing carcinogenesis}

Dysbiosis (microbiota alterations) or antibiotics treatment has been suggested to modify the microbiota ability to metabolize oestrogens, which in turn, is thought to be the non-inflammatory mechanism whereby the microflora adjusts distant malignancies [60]. Furthermore, antibiotics could influence cancer risk through many mechanisms [61]. For instance, it has been found that the use of antibiotics could decrease the ability of intestinal microbiota to metabolize phytochemicals into compounds that might offer protection against cancer $[62,63]$. However, the correlation between antibiotics use and cancer risk could be attributed to the effects of antimicrobials on inflammation and the functions of the immune system $[61,64]$.

The microbiota has been approved to be direct or indirect inducers of inflammation development and maintenance, which has been widely accepted to be one of the cancer hallmarks. Inflammation has been demonstrated to stimulate cancer via increasing genetic instability. Approximately, $16 \%$ of human cancers throughout the world are caused by infectious agents, especially those associated with chronic inflammation; with higher percentages in the developing countries than in the developed ones [65]. The microbiota may enhance cancer-promoting conditions, for example, obesity and metabolic syndromes, and modification of numerous inflammatory and immune mechanisms that control the initiation and progression of cancer [66].

The development and progression of cancer at various body sites, such as stomach, colon, liver, lung, and skin have been linked to microbiome and microbial imbalance $[25,66]$. Dysbiosis disturbs the symbiotic relationship between the resident microbiota and the host [67]. It has been shown that dysbiosis is able to dysregulate immune and inflammatory responses of the host against bacteria as well as impairing the control of pathogenic organisms leading to severe acute and chronic tissue damage [68]. On the other hand, commensal bacteria have been suggested to become pathogenic when they translocate through the mucosa or under certain conditions, for example, 
immunodeficiency [69]. Eventually, high incidence of certain types of human neoplasms can occur due to chronic bacterial infections [27]. Hence, tumour development seems to be a side effect of the bacterial infection [70]. It has been shown that mice undergoing intestinal dysbiosis lost their ability to produce or respond to IL-18, and the mice were vulnerable to colon cancer induced by chemicals $[30,71,72]$.

Various bacterial genera have been linked with neoplasms, and the infections resulting from these bacteria have mutual characteristics [73]. However, the time between the acquisition of bacterial infection and cancer occurrence is often decades. Carcinogenesis appears to result from the long-lasting interactions between the infectious agent, host's immune response, and/or host susceptibility $[15,73,74]$.

Microbes have been proposed to have an extraordinary pleo-morphological tendency, which might be important for cancer development. Many bacterial spp. have been verified to play a role as tumour promoters or carcinogens [75]. Some important bacterial spp. that are capable of causing cancer are presented in the table below. Convincing evidence have linked gastric cancer and mucosa-associated lymphoid tissue (MALT) lymphoma with the infections of Helicobacter pylori [76-78]. Hepatobiliary carcinoma [79] and gallbladder cancer have been attributed to Salmonella Typhi infections $[15,80,81]$. Concerning gastrointestinal tract, Campylobacter jejuni has been related to small intestinal lymphomas [82]. While S. bovis has been linked to colon cancer (83-85), Citrobacter rodentium has been associated with human colorectal cancer [86]. Fusobacterium nucleatum, which is a Gram-negative anaerobic oral commensal and periodontal pathogen, has been implicated in colorectal neoplasia [87-88]. Moreover, Chlamydia pneumoniae as well as Mycobacterium tuberculosis have been correlated with lung cancer [89-92]. Ocular lymphomas have been attributed to infections with Chlamydia psittaci [93]. Importantly, E. coli, S. mitis, and Bacillus subtilis together have been reported to promote tumour cell invasion and angiogenesis along with tumour metastasis [94]. Altogether, according to what has been mentioned above, preventing or treating the infection may prevent the cancer from occurrence. However, the vast majority of individuals infected with cancer-causing bacteria will not develop cancer [73].

\subsection{Bacterial strategies for carcinogenesis}

The ability of the inhabitant microorganisms to influence the differentiation, migration, and functions of myeloid cells can mediate the alterations in the immune response to infections or neoplasms [96-98]. Carcinogenesis may be induced by bacteria or their 
TABLE 1: Bacterial spp. associated with certain types of cancer.

Bacteria

Campylobacter jejuni

Chlamydia pneumoniae

Chlamydia psittaci

Citrobacter rodentium

Fusobacterium nucleatum

Helicobacter pylori

Mycobacterium tuberculosis

Porphyromonas gingivalis

Salmonella Typhi

Salmonella Typhimurium

Streptococcus bovis

\section{Cancer}

Small intestinal lymphoma

Lung cancer

Ocular lymphomas

Human colorectal cancer

Human colorectal cancer

Gastric carcinoma,

Mucosa-associated lymphoid

tissue lymphoma

Lung cancer

Pancreatic cancer

Hepatobiliary carcinoma,

Gallbladder cancer

Hepatobiliary carcinoma

Colon cancer

\section{References}

Mesnard et al. (2012) [82]

Koyi et al. (2001) [89]

Ferreri et al. (2004) [93]

Luperchio et al. (2000) [86]

Kostic et al. (2013) [87]

Correa et al. (1990) [76] Crowe (2005) [78]

Gupta et al. (2016) [92]

Jacob (2016) [95]

Caygill et al. (1995) [79] Dutta et al. (2000) [80]

Caygill et al. (1995) [79]

Zarkin et al. (1990) [83]

secreting products through many mechanisms, including, immune evasion, immune suppression, and chronic inflammation [73].

The mechanisms of carcinogenesis have been described well for a number of bacterial spp., such as E. coli (enteropathogenic), Enterococcus faecalis, S. gallolyticus, $B$. fragilis (enterotoxigenic), and Fusobacterium spp. [87, 99, 100]. Individually, these commensal bacteria could induce carcinogenesis, however, through diverse mechanisms, for example, quorum sensing and the secretion of antibacterial factors and hormones, these bacteria may synergistically cause modulation to the composition of microflorainducing disease-promoting dysbiosis [100]. Chronic inflammation has been suggested to be associated with the increased rates of DNA turnover predisposing cells, secondary to the malignant transformation following the exposure to primary carcinogens [101]. Interestingly, cancer stimulation has been linked to inflammation through the nitrogen and reactive oxygen species (ROS) produced by the infecting agents. These chemicals have been shown to provoke the occurrence of single-stranded DNA or doublestranded DNA breaks or DNA cross-links, which subsequently might drive mutations in tumour suppressor genes or oncogenes, that is, genomic instability $[102,103]$.

An important role of gut commensal microorganisms in cancer has been revealed through their modulation of local intestinal carcinogenesis as well as enhancing carcinogenesis in distant sterile sites through the alteration of tumour necrosis factor (TNF), oxidative stress, and leukocyte, or epithelial cell genotoxicity [104, 105]. In addition, the gut microbiota has been associated with epithelial cell damage, mutation, and genomic 
instability, in part due to inducing the secretion of DNA-damaging ROS and nitrogen species, and by downregulating the DNA repair genes expression [102].

Strategies that enable bacteria to evade the host's immune system are also available, with the toxins being not the only strategy, which will be discussed further. The immune system can be evaded via biofilm formation, an example is uropathic $E$. coli, whose biofilm protects it from the immune system rendering it resistant to antibiotics and making its infection to be chronic [106]. Furthermore, the oral pathogens, Capnocytophaga spp., can inhibit the migration of polymorphonuclear leukocytes; thereby these species evade phagocytosis [107]. With respect to the immune suppression, it was documented that strains of Capnocytophaga ochracea, have the capability to hydrolytically degrading immunoglobulin A $(\lg A)$ subclass 1 of the oral cavity. This characteristic might augment colonization and invasion of oral lesions by many other bacteria [108].

\subsection{Bacterial products that induce malignant transformation}

\subsubsection{Bacterial toxins}

Many bacterial spp. are well-known for producing toxins, some of these products have been proved to have carcinogenic effects. Bacterial toxins have the ability to kill cells or at reduced levels are capable of altering cellular processes that control proliferation, differentiation, and apoptosis. These alterations have been linked with carcinogenesis and may either inhibit normal cell controls or stimulate cellular abnormalities [109]. Many bacterial toxins perturb the control of cell growth by disrupting the cellular signals. Due to their induction of inflammation, toxins are considered prospective tumour promoters [110]. Cancer development has been attributed to a number of bacterial protein toxins because of their ability to cause DNA damage [70]. However, DNA damage itself might not be adequate to raise cancer development. The most harmful type of DNA damage is double-strand breaks generated by genotoxins, ROS, and ionizing radiation [3].

Interestingly, toxins secreted by various bacteria isolated from normal adjacent breast cancer tissue are able to induce DNA double-stranded breaks [111]. These bacteria included several isolates of $E$. coli and one S. epidermidis that caused DNA damage due to their ability to produce colibactin, which could cause genomic instability [112], and later lead to cancer development [113]. Certain pathogenic E. coli strains that colonize more frequently colon cancers release cytotoxic necrotizing factor (CNF) [114]. This toxin is an example of cell-cycle stimulators that have been classified as cyclomodulins. The 
toxin has been found to interfere with cell differentiation and promote cellular proliferation [109] by triggering $G_{1}-S$ transition and consequently induces DNA replication and disrupts the cell cycle of the host. However, the cells do not increase in number, but they become multinucleated, possibly due to the ability of the toxin to inhibit cell differentiation and apoptosis [115].

In contrast, other toxins are cell-cycle inhibitors, such as the cycle inhibiting factor (Cif) and cytolethal distending toxins (CDTs). Both toxins impede mitosis and compromise the immune system through inhibiting lymphocytes clonal expansion [109]. Concerning the Cif toxin, it is found in enteropathogenic (EPEC) and enterohaemorrhagic (EHEC) $E$. coli [116]. It causes cell arrest at the G2/M phase [117] resulting in host cell modifications that cause the host cell membrane to attach to the cytoskeleton. This anchoring of the cytoskeleton blocks mitosis and leads to cellular and nuclear expansion [109, 117]. The CDTs toxin are secreted by several spp. of Gram-negative bacteria, including $E$. coli, Campylobacter jejuni, and S. Typhi [116]. The CDT holotoxin is composed of three different subunits: Cdt A, Cdt B, and Cdt C, which are encoded by three genes located on the same operon [118]. It has been shown that the CDT and its Cdt B unit are a DNAse that generates double-stranded DNA breaks resulting in cell cycle arrest, mostly at the $\mathrm{G}_{2}$ checkpoint [119].

Another toxin is vacuolating cytotoxin $\mathrm{A}$ (VacA), encoded by vacA gene in almost all strains of $H$. pylori, is greatly correlated with pre-cancerous intestinal metaplasia and genetic adenocarcinoma [120]. Both VacA and cytotoxin-associated gene-A (CagA) protein toxins, which are virulence factors of $H$. pylori, through their expression for a long time, generate pathologic intestinal hyperplasia in adults [121]. A role for S. Typhi has been confirmed in colon cancer through its protein toxin Avirulence protein $A$ (AvrA) [122]. In addition, the increased risk of colon carcinoma has been linked with the chronic infection with the enterotoxigenic $B$. fragilis (ETBF) due to its production of a metalloprotease protein toxin known as $B$. fragilis toxin (BFT) [123]

\subsubsection{Bacterial enzymes}

Some enzymes produced by bacteria are potential carcinogens. One such enzyme is peptidyl arginine deaminases (PAD), which are produced by oral bacteria and associated with pancreatic cancer [95]. Another enzyme is B-glucuronidase, which is synthesized by many bacteria such as the Escherichia/Shigella bacterial group, a member of the Proteobacteria phylum, as well as Clostridium leptum and Clostridium coccoides, which belong to the Firmicutes phylum. It has been found that numerous microorganisms 
correlated with breast cancer share the enzymatic activity of ß-glucuronidase, which impedes oestrogens conjugation, among other compounds, leaving them as biologically active hormones [124]. Likewise, a considerable role of ß-glucuronidase has been demonstrated through its de-conjugation of bisphenol-A, which is one of endocrine disrupting chemicals, leading to increasing the time of its persistence in an organism. Some endocrine compounds have been suggested to induce gut microbiota modulations and alter their metabolites, leading to increased inflammation [125].

\subsubsection{Other bacterial products}

The FadA adhesin/invasin, produced by $F$. nucleatum, is required for binding and invasion of normal and cancerous host cells. It is the best characterized virulence factor whose level has been shown to be elevated in normal tissues adjacent to adenoma and carcinoma compared to normal individuals without tumour or inflammation [99]. Other factors that promote tumour cell invasion and angiogenesis include quorum-sensing peptides such as extracellular death factors (EDF) from E. coli, phosphate regulator $G$ (PhrG) from Bacillus subtilis, and competence stimulating peptide (CSP) from S. mitis [94]. These quorum-sensing peptides act through downregulating microRNA-222 and starting angiogenesis, which stimulates neovascularization leading to tumour metastasis [126].

\section{Conclusions}

From the data reviewed earlier, it can be concluded that commensal microbiota plays an important role in the prevention of diseases including cancer. The symbiotic relationships between the microbiota and the host confer benefits to the last, in which some bacteria act as probiotics that sustain host health. Inversely, microbiome alterations (dysbiosis) have been found to interrupt that symbiotic correlation between the host and the inhabitant microbiota. Various mechanisms exist by which bacteria and their secreting products could induce carcinogenesis, including chronic infection, immune evasion, and immune suppression. Evidence has linked many bacterial infections to carcinogenesis, such as H. pylori, S. Typhi, C. jejuni, C. psittaci, C. pneumoniae, M. tuberculosis, C. rodentium, F. nucleatum, and S. bovis. However, the impacts of microflora on cancer treatment need to be extensively discussed in separate reviews. This tumour-associated microbiota might have duel effects on cancer therapies, both negatively and positively, which are not described here. 


\section{Recommendations}

The authors recommend investigating the correlation between the commensal microbiome, antibiotics uptake, and cancer occurrence, especially in Iraq. Another important issue is evaluating the effects of the microbiome on the currently used anticancer agents. More attention should be paid for the role that might be played by commensal bacteria on tumour progression or tumour regression; this can be achieved by doing more clinical trials in this field, by investigating the possible fungal spp. and yeasts that might reside tumour tissues, and studying their influences on carcinogenesis along with cancer therapies.

\section{Author Contributions}

Both the authors contributed equally to the study.

\section{Conflicts of Interest}

The authors declare no conflict of interest.

\section{References}

[1] Howlader, N., Noone, A., and Krapcho, M. (2014). SEER Cancer Statistics Review, 1975-2012. Bethesda, Md, USA: National Cancer Institute.

[2] Grivennikov, S. I., Greten, F. R., and Karin, M. (2010). Immunity, inflammation, and cancer. Cell, vol. 140, pp. 883-889.

[3] Hanahan, D. and Weinberg, R. A. (2011). Hallmarks of cancer: the next generation. Cell, vol. 144, pp. 646-674.

[4] Jain, R. K. (2001). New approaches for the treatment of the cancer. Advanced Drug Delivery Reviews, vol. 36, pp. 149-168.

[5] Felgner, S., Kocijancic, D., Frahm, M., et al. (2016). Bacteria in Cancer Therapy: Renaissance of an Old Concept. International Journal of Medical Microbiology, vol. 2016, p. 8451728.

[6] Nauts, H. C. and McLaren, J. R. (1990). Coley toxins-the first century. Advances in Experimental Medicine and Biology, vol. 267, pp. 483-500.

[7] Fernandez, M. F., Reina-Perez, I., Astorga, J. M., et al. (2018). Breast cancer and its relationship with the microbiota. International Journal of Environmental Research 
and Public Health, vol. 15, no. 8, pii: E1747.

[8] Patyar, S., Joshi, R., Byrav, D. S., et al. (2010). Bacteria in cancer therapy: a novel experimental strategy. Journal of Biomedical Science, vol. 17, no. 1, pp. 21.

[9] Toso, J. F., Gill, V. J., Hwu, P., et al. (2002). Phase I study of the intravenous administration of attenuated Salmonella typhimurium to patients with metastatic melanoma. Journal of Clinical Oncology, vol. 20, pp. 142-152.

[10] Nemunaitis, J., Cunningham, C., Senzer, N., et al. (2003). Pilot trial of genetically modified, attenuated Salmonella expressing the E. coli cytosine deaminase gene in refractory cancer patients. Cancer Gene Therapy, vol. 10, pp. 737-744.

[11] Baban, C. K., Cronin, M., O'Hanlon, D., et al. (2010). Bacteria as vectors for gene therapy of cancer. Bioengineered Bugs, vol. 1, pp. 385-394.

[12] Liu, S., Xu, X., Zeng, X., et al. (2014). Tumor-targeting bacterial therapy: a potential treatment for oral cancer. Oncol Letters, vol. 8, pp. 2359-2366.

[13] Lavigne, M. D. and Gorecki, D. C. (2006). Emerging vectors and targeting methods for nonviral gene therapy. Expert Opinion on Emerging Drugs, vol. 11, pp. 541-557.

[14] Ptak, C. and Petronis, A. (2008). Epigenetics and complex disease: from etiology to new therapeutics. Annual Review of Pharmacology and Toxicology, vol. 48, pp. 257-276.

[15] Lax, A. J. and Thomas, W. (2002). How bacteria could cause cancer: one step at a time. Trends in Microbiology, vol. 10, pp. 293-299.

[16] Vogelstein, B., Papadopoulos, N., Velculescu, V. E., et al. (2013). Cancer genome landscapes. Science, vol. 339, pp. 1546-1558.

[17] Trinchieri, G. (2012). Cancer and inflammation: an old intuition with rapidly evolving new concepts. Annual Review of Immunology, vol. 30, pp. 677-706.

[18] Backhed, F., Ley, R. E., Sonnenburg, J. L., et al. (2005). Host-bacterial mutualism in the human intestine. Science, vol. 307, pp. 1915-1920.

[19] Human Microbiome Project Consortium. (2012). Structure, function and diversity of the healthy human microbiome. Nature, vol. 486, pp. 207-214.

[20] Schlaeppi, K. and Bulgarelli, D. (2015). The plant microbiome at work. Molecular Plant-Microbe Interactions, vol. 28, pp. 212-217.

[21] Eckburg, P. B., Bik, E. M., Bernstein, C. N., et al. (2005). Diversity of the human intestinal microbial flora. Science, vol. 308, pp. 1635-1638.

[22] Lax, A. J. (2005). Opinion: bacterial toxins and cancer-a case to answer? Nature Reviews Microbiology, vol. 3, pp. 343-349. 
[23] Brook, I. (1990). Bacteria from solid tumours. Journal of Medical Microbiology, vol. 32, pp. 207-210.

[24] Urbaniak, C., Cummins, J., Brackstone, M., et al. (2014). Microbiota of human breast tissue. Applied and Environmental Microbiology, vol. 80, pp. 3007-3014.

[25] Hieken, T. J., Chen, J., Hoskin, T. L., et al. (2016). The microbiome of aseptically collected human breast tissue in benign and malignant disease. Scientific Reports, vol. 6, p. 30751.

[26] Shaker, D. A. and Lafta, I. J. (2018). Methicillin-resistant Staphylococcus epidermidis isolated from breast tumors of Iraqi patients. International Journal of Medical Research and Health Sciences, vol. 7, no. 7, pp. 54-62.

[27] Guidi, R., Guerra, L., Levi, L., et al. (2013). Chronic exposure to the cytolethal distending toxins of Gram-negative bacteria promotes genomic instability and altered DNA damage response. Cellular Microbiology, vol. 15, pp. 98-113.

[28] Kamada, N., Kim, Y. G., Sham, H. P., et al. (2012). Regulated virulence controls the ability of a pathogen to compete with the gut microbiota. Science, vol. 336, pp. 1325-1329.

[29] Kamada, N., Chen, G. Y., Inohara, N., et al. (2013). Control of pathogens and pathobionts by the gut microbiota. Nature Immunology, vol. 14, pp. 685-690.

[30] Salcedo, R., Worschech, A., Cardone, M., et al. (2010). MyD88-mediated signaling prevents development of adenocarcinomas of the colon: role of interleukin 18. Journal of Experimental Medicine, vol. 207, pp. 1625-1636.

[31] Ege, M. J., Mayer, M., Normand, A. C., et al. (2011). Exposure to environmental microorganisms and childhood asthma. The New England Journal of Medicine, vol. 364, pp. 701-709.

[32] Olszak, T., An, D., Zeissig, S., et al. (2012). Microbial exposure during early life has persistent effects on natural killer T cell function. Science, vol. 336, pp. 489-493.

[33] Serbina, N. V., Jia, T., Hohl, T. M., et al. (2008). Monocyte-mediated defense against microbial pathogens. Annual Review of Immunology, vol. 26, pp. 421-452.

[34] Avila, M., Ojcius, D. M., and Yilmaz, O. (2009). The oral microbiota: living with a permanent guest. DNA and Cell Biology, vol. 28, pp. 405-411.

[35] Hajishengallis, G., Liang, S., Payne, M. A., et al. (2011). Low-abundance biofilm species orchestrates inflammatory periodontal disease through the commensal microbiota and complement. Cell Host \& Microbe, vol. 10, pp. 497-506.

[36] Hajishengallis, G. and Lamont, R. J. (2014). Breaking bad: manipulation of the host response by Porphyromonas gingivalis. European Journal of Immunology, vol. 44, pp. 328-338. 
[37] Iwase, T., Uehara, Y., Shinji, H., et al. (2010). Staphylococcus epidermidis Esp inhibits Staphylococcus aureus biofilm formation and nasal colonization. Nature, vol. 465, pp. 346-349.

[38] Zipperer, A., Konnerth, M. C., Laux, C., et al. (2016). Human commensals producing a novel antibiotic impair pathogen colonization. Nature, vol. 535, pp. 511-516.

[39] Xuan, C., Shamonki, J. M., Chung, A., et al. (2014). Microbial dysbiosis is associated with human breast cancer. PLOS One, vol. 9, e83744.

[40] Belkaid, Y. and Naik, S. (2013) Compartmentalized and systemic control of tissue immunity by commensals. Nature Immunology, vol. 14, pp. 646-653.

[41] Naik, S., Bouladoux, N., Wilhelm, C., et al. (2012). Compartmentalized control of skin immunity by resident commensals. Science, vol. 337, pp. 1115-1119.

[42] Chu, H. and Mazmanian, S. K. (2013). Innate immune recognition of the microbiota promotes host-microbial symbiosis. Nature Immunology, vol. 14, pp. 668-675.

[43] Lai, Y., Di Nardo, A., Nakatsuji, T., et al. (2009). Commensal bacteria regulate Tolllike receptor 3-dependent inflammation after skin injury. Nature Medicine, vol. 15, pp. 1377-1382.

[44] Lai, Y., Cogen, A. L., Radek, K. A., et al. (2010). Activation of TLR2 by a small molecule produced by Staphylococcus epidermidis increases antimicrobial defense against bacterial skin infections. Journal of Investigative Dermatology, vol. 130, pp. 22112221.

[45] Wanke, I., Steffen, H., Christ, C., et al. (2011). Skin commensals amplify the innate immune response to pathogens by activation of distinct signaling pathways. Journal of Investigative Dermatology, vol. 131, pp. 382-390.

[46] Li, D., Lei, H., Li, Z., et al. (2013). A novel lipopeptide from skin commensal activates TLR2/CD36-p38 MAPK signaling to increase antibacterial defense against bacterial infection. PLOS ONE, vol. 8, e58288.

[47] Naik, S., Bouladoux, N., Linehan, J. L., et al. (2015). Commensal-dendritic-cell interaction specifies a unique protective skin immune signature. Nature, vol. 520, pp. 104-108.

[48] Cogen, A. L., Yamasaki, K., Sanchez, K. M., et al. (2010). Selective antimicrobial action is provided by phenol-soluble modulins derived from Staphylococcus epidermidis, a normal resident of the skin. Journal of Investigative Dermatology, vol. 130, pp. $192-200$

[49] Nakatsuji, T., Chen, T. H., Narala, S., et al. (2017). Antimicrobials from human skin commensal bacteria protect against Staphylococcus aureus and are deficient in atopic dermatitis. Science Translational Medicine, vol. 9. 
[50] Cogen, A. L., Yamasaki, K., Muto, J., et al. (2010). Staphylococcus epidermidis antimicrobial delta-toxin (phenol-soluble modulin-gamma) cooperates with host antimicrobial peptides to kill group A Streptococcus. PLOS ONE, vol. 5, e8557.

[51] Nakatsuji, T., Chen, T. H., Butcher, A. M., et al. (2018). A commensal strain of Staphylococcus epidermidis protects against skin neoplasia. Science Advances, vol. 4, no. 3, eaao4502.

[52] Kalina, U., Koyama, N., Hosoda, T., et al. (2002). Enhanced production of IL-18 in butyrate-treated intestinal epithelium by stimulation of the proximal promoter region. European Journal of Immunology, vol. 32, pp. 2635-2643.

[53] Singh, N., Gurav, A., Sivaprakasam, S., et al. (2014). Activation of Gpr109a, receptor for niacin and the commensal metabolite butyrate, suppresses colonic inflammation and carcinogenesis. Immunity, vol. 40, pp. 128-139.

[54] Huber, S., Gagliani, N., Zenewicz, L. A., et al. (2012). IL-22BP is regulated by the inflammasome and modulates tumorigenesis in the intestine. Nature, vol. 491, pp. 259-263.

[55] Saleh, M. and Trinchieri, G. (2011). Innate immune mechanisms of colitis and colitisassociated colorectal cancer. Nature Reviews Immunology, vol. 11, pp. 9-20.

[56] Kirchberger, S., Royston, D. J., Boulard, O., et al. (2013). Innate lymphoid cells sustain colon cancer through production of interleukin-22 in a mouse model. Journal of Experimental Medicine, vol. 210, pp. 917-931.

[57] Smith, P. M., Howitt, M. R., Panikov, N., et al. (2013). The microbial metabolites, shortchain fatty acids, regulate colonic Treg cell homeostasis. Science, vol. 341, pp. 569573.

[58] Round, J. L. and Mazmanian, S. K. (2010). Inducible Foxp3+ regulatory T-cell development by a commensal bacterium of the intestinal microbiota. Proceedings of the National Academy of Sciences of the United States of America, vol. 107, pp. 12204-12209.

[59] Mazmanian, S. K., Round, J. L., and Kasper, D. L. (2008). A microbial symbiosis factor prevents intestinal inflammatory disease. Nature, vol. 453, pp. 620-625.

[60] Plottel, C. S. and Blaser, M. J. (2011). Microbiome and malignancy. Cell Host \& Microbe, vol. 10, pp. 324-335.

[61] Velicer, C. M., Lampe, J. W., Heckbert, S. R., et al. (2003). Hypothesis: is antibiotic use associated with breast cancer? Cancer Causes \& Control, vol. 14, pp. 739-747.

[62] Shapiro, T. A., Fahey, J. W., Wade, K. L., et al. (1998). Human metabolism and excretion of cancer chemoprotective glucosinolates and isothiocyanates of 
cruciferous vegetables. Cancer Epidemiology, Biomarkers \& Prevention, vol. 7, pp. $1091-1100$.

[63] Kilkkinen, A., Pietinen, P., Klaukka, T., et al. (2002). Use of oral antimicrobials decreases serum enterolactone concentration. American Journal of Epidemiology, vol. 155, pp. 472-477.

[64] Reed, M. J. and Purohit, A. (2001). Aromatase regulation and breast cancer. Clinical Endocrinology, vol. 54, pp. 563-571.

[65] de Martel, C., Ferlay, J., Franceschi, S., et al. (2012). Global burden of cancers attributable to infections in 2008: a review and synthetic analysis. The Lancet Oncology, vol. 13, pp. 607-615.

[66] Dzutsev, A., Goldszmid, R. S., Viaud, S., et al. (2015). The role of the microbiota in inflammation, carcinogenesis, and cancer therapy. European Journal of Immunology, vol. 45, pp. 17-31.

[67] Underwood, M. A. (2014). Intestinal dysbiosis: novel mechanisms by which gut microbes trigger and prevent disease. Preventive Medicine, vol. 65, pp. 133-137.

[68] Frank, D. N., St Amand, A. L., Feldman, R. A., et al. (2007). Molecular-phylogenetic characterization of microbial community imbalances in human inflammatory bowel diseases. Proceedings of the National Academy of Sciences of the United States of America, vol. 104, pp. 13780-13785.

[69] Backhed, F., Ley, R. E., Sonnenburg, J. L., et al. (2005). Host-bacterial mutualism in the human intestine. Science, vol. 307, pp. 1915-1920.

[70] Rosadi, F., Fiorentini, C., and Fabbri, A. (2016). Bacterial protein toxins in human cancers. Pathogens and Disease, vol. 74, ftv105.

[71] Allen, I. C., TeKippe, E. M., Woodford, R. M., et al. (2010). The NLRP3 inflammasome functions as a negative regulator of tumorigenesis during colitis-associated cancer. Journal of Experimental Medicine, vol. 207, pp. 1045-1056.

[72] Elinav, E., Strowig, T., Kau, A. L., et al. (2011). NLRP6 inflammasome regulates colonic microbial ecology and risk for colitis. Cell, vol. 145, pp. 745-757.

[73] Kuper, H., Adami, H. O., and Trichopoulos, D. (2000). Infections as a major preventable cause of human cancer. Journal of Internal Medicine, vol. 248, pp. 171-183.

[74] Correa, P. and Miller, M. J. (1998). Carcinogenesis, apoptosis and cell proliferation. British Medical Bulletin, vol. 54, pp. 151-162.

[75] Cover, T. L., Glupczynski, Y., Lage, A. P., et al. (1995). Serologic detection of infection with cagA+ Helicobacter pylori strains. Journal of Clinical Microbiology, vol. 33, pp. 1496-1500. 
[76] Correa, P., Fox, J., Fontham, E., et al. (1990). Helicobacter pylori and gastric carcinoma. Serum antibody prevalence in populations with contrasting cancer risks. Cancer, vol. 66, pp. 2569-2574.

[77] Montalban, C., Santon, A., Boixeda, D., et al. (2001). Regression of gastric high grade mucosa associated lymphoid tissue (MALT) lymphoma after Helicobacter pylori eradication. Gut, vol. 49, pp. 584-587.

[78] Crowe, S. E. (2005). Helicobacter infection, chronic inflammation, and the development of malignancy. Current Opinion in Gastroenterology, vol. 21, pp. 32-38.

[79] Caygill, C. P., Braddick, M., Hill, M. J., et al. (1995). The association between typhoid carriage, typhoid infection and subsequent cancer at a number of sites. European Journal of Cancer Prevention, vol. 4: 187-193.

[80] Dutta, U., Garg, P. K., Kumar, R., et al. (2000). Typhoid carriers among patients with gallstones are at increased risk for carcinoma of the gallbladder. The American Journal of Gastroenterology, vol. 95, pp. 784-787.

[81] Shukla, V. K., Singh, H., Pandey, M., et al. (2000). Carcinoma of the gallbladder-is it a sequel of typhoid? Digestive Diseases and Sciences, vol. 45, pp. 900-903.

[82] Mesnard, B., De Vroey, B., Maunoury, V., et al. (2012). Immunoproliferative small intestinal disease associated with Campylobacter jejuni. Digestive and Liver Disease, vol. 44, pp. 799-800.

[83] Zarkin, B. A., Lillemoe, K. D., Cameron, J. L., et al. (1990). The triad of Streptococcus bovis bacteremia, colonic pathology, and liver disease. Annals of Surgery, vol. 211, pp. 786-791.

[84] Ellmerich, S., Scholler, M., Duranton, B., et al. (2000). Promotion of intestinal carcinogenesis by Streptococcus bovis. Carcinogenesis, vol. 21, pp. 753-756.

[85] Gold, J. S., Bayar, S., and Salem, R. R. (2004). Association of Streptococcus bovis bacteremia with colonic neoplasia and extracolonic malignancy. The Archives of Surgery, vol. 139, pp. 760-765.

[86] Luperchio, S. A., Newman, J. V., Dangler, C. A., et al. (2000). Citrobacter rodentium, the causative agent of transmissible murine colonic hyperplasia, exhibits clonality: synonymy of $C$. rodentium and mouse-pathogenic Escherichia coli. Journal of Clinical Microbiology, vol. 38, pp. 4343-4350.

[87] Kostic, A. D., Chun, E., Robertson, L., et al. (2013). Fusobacterium nucleatum potentiates intestinal tumorigenesis and modulates the tumor-immune microenvironment. Cell Host \& Microbe, vol. 14, pp. 207-215.

[88] McCoy, A. N., Araujo-Perez, F., Azcarate-Peril, A., et al. (2013). Fusobacterium is associated with colorectal adenomas. PLOS ONE, vol. 8, e53653. 
[89] Koyi, H., Branden, E., Gnarpe, J., et al. (2001). An association between chronic infection with Chlamydia pneumoniae and lung cancer. a prospective 2-year study. APMIS, vol. 109, pp. 572-580.

[90] Anttila, T., Koskela, P., Leinonen, M., et al. (2003). Chlamydia pneumoniae infection and the risk of female early-onset lung cancer. International Journal of Cancer, vol. 107, pp. 681-682.

[91] Littman, A. J., White, E., Jackson, L. A., et al. (2004). Chlamydia pneumoniae infection and risk of lung cancer. Cancer Epidemiology, Biomarkers \& Prevention, vol. 13, pp. 1624-1630.

[92] Gupta, P. K., Tripathi, D., Kulkarni, S., et al. (2016). Mycobacterium tuberculosis H37Rv infected THP-1 cells induce epithelial mesenchymal transition (EMT) in lung adenocarcinoma epithelial cell line (A549). Cellular Immunology, vol. 300, pp. 33-40.

[93] Ferreri, A. J., Guidoboni, M., Ponzoni, M., et al. (2004). Evidence for an association between Chlamydia psittaci and ocular adnexal lymphomas. Journal of the National Cancer Institute, vol. 96, pp. 586-594.

[94] De Spiegeleer, B., Verbeke, F., D’Hondt, M., et al. (2015). The quorum sensing peptides PhrG, CSP and EDF promote angiogenesis and invasion of breast cancer cells in vitro. PLOS ONE, vol. 10, e0119471.

[95] Jacob, J. A. (2016). Study links periodontal disease bacteria to pancreatic cancer risk. JAMA, vol. 315, pp. 2653-2654.

[96] lida, N., Dzutsev, A., Stewart, C. A., et al. (2013). Commensal bacteria control cancer response to therapy by modulating the tumor microenvironment. Science, vol. 342, pp. 967-970.

[97] Mukherji, A., Kobiita, A., Ye, T., et al. (2013). Homeostasis in intestinal epithelium is orchestrated by the circadian clock and microbiota cues transduced by TLRs. Cell, vol. 153, pp. 812-827.

[98] Khosravi, A., Yanez, A., Price, J. G., et al. (2014). Gut microbiota promote hematopoiesis to control bacterial infection. Cell Host \& Microbe, vol. 15, pp. 374-381.

[99] Rubinstein, M. R., Wang, X., Liu, W., et al. (2013). Fusobacterium nucleatum promotes colorectal carcinogenesis by modulating E-cadherin/beta-catenin signaling via its FadA adhesin. Cell Host \& Microbe, vol. 14, pp. 195-206.

[100] Sears, C. L. and Garrett, W. S. (2014). Microbes, microbiota, and colon cancer. Cell Host \& Microbe, vol. 15, pp. 317-328.

[101] Mackowiak, P. A. (1987). Microbial oncogenesis. The American Journal of Medicine, vol. 82, pp. 79-97. 
[102] Hussain, S. P., Hofseth, L. J., and Harris, C. C. (2003). Radical causes of cancer. Nature Reviews Cancer, vol. 3, pp. 276-285.

[103] Schetter, A. J., Heegaard, N. H., and Harris, C. C. (2010). Inflammation and cancer: interweaving microRNA, free radical, cytokine and p53 pathways. Carcinogenesis, vol. 31, pp. 37-49.

[104] Poutahidis, T., Cappelle, K., Levkovich, T., et al. (2013). Pathogenic intestinal bacteria enhance prostate cancer development via systemic activation of immune cells in mice. PLOS ONE, vol. 8, e73933.

[105] Yamamoto, M. L., Maier, I., Dang, A. T., et al. (2013). Intestinal bacteria modify lymphoma incidence and latency by affecting systemic inflammatory state, oxidative stress, and leukocyte genotoxicity. Cancer Research, vol. 73, pp. 4222-4232.

[106] Mulvey, M. A., Schilling, J. D., and Hultgren, S. J. (2001). Establishment of a persistent Escherichia coli reservoir during the acute phase of a bladder infection. Infection and Immunity, vol. 69, pp. 4572-4579.

[107] Shurin, S. B., Socransky, S. S., Sweeney, E., et al. (1979). A neutrophil disorder induced by capnocytophaga, a dental microorganism. The New England Journal of Medicine, vol. 301, pp. 849-854.

[108] Kilian, M. (1981). Degradation of immunoglobulins A2, A2, and $G$ by suspected principal periodontal pathogens. Infection and Immunity, vol. 34, pp. 757-765.

[109] Nougayrede, J. P., Taieb, F., De Rycke, J., et al. (2005). Cyclomodulins: bacterial effectors that modulate the eukaryotic cell cycle. Trends in Microbiology, vol. 13, pp. $103-110$

[110] Lax, A. J. (2005). Opinion: bacterial toxins and cancer-a case to answer? Nature Reviews Microbiology, vol. 3, pp. 343-349.

[111] Urbaniak, C., Gloor, G. B., Brackstone, M., et al. (2016). The microbiota of breast tissue and its association with breast cancer. Applied and Environmental Microbiology, vol. 82, pp. 5039-5048.

[112] Koller, V. J., Marian, B., Stidl, R., et al. (2008). Impact of lactic acid bacteria on oxidative DNA damage in human derived colon cells. Food and Chemical Toxicology, vol. 46, pp. 1221-1229.

[113] Putze, J., Hennequin, C., Nougayrede, J. P., et al. (2009). Genetic structure and distribution of the colibactin genomic island among members of the family Enterobacteriaceae. Infection and Immunity, 77, pp. 4696-4703.

[114] Buc, E., Dubois, D., Sauvanet, P., et al. (2013). High prevalence of mucosa-associated E. coli producing cyclomodulin and genotoxin in colon cancer. PLOS ONE, vol. 8, e56964. 
[115] Oswald, E., Sugai, M., Labigne, A., et al. (1994). Cytotoxic necrotizing factor type 2 produced by virulent Escherichia coli modifies the small GTP-binding proteins Rho involved in assembly of actin stress fibers. Proceedings of the National Academy of Sciences of the United States of America, vol. 91, pp. 3814-3818.

[116] Smith, J. L. and Bayles, D. O. (2006). The contribution of cytolethal distending toxin to bacterial pathogenesis. Critical Reviews in Microbiology, vol. 32, pp. 227-248.

[117] Marches, O., Ledger, T. N., Boury, M., et al. (2003). Enteropathogenic and enterohaemorrhagic Escherichia coli deliver a novel effector called Cif, which blocks cell cycle G2/M transition. Molecular Microbiology, vol. 50, pp. 1553-1567.

[118] Thelestam, M. and Frisan, T. (2006). Cytolethal distending toxins, in Alouf J, Popoff M (ed.) The comprehensive sourcebook of bacterial protein toxins, pp. 448-467. San Diego, USA: Elsevier, Academic Press.

[119] Haghjoo, E. and Galan, J. E. (2004). Salmonella typhi encodes a functional cytolethal distending toxin that is delivered into host cells by a bacterial-internalization pathway. Proceedings of the National Academy of Sciences of the United States of America, vol. 101, pp. 4614-4619.

[120] Winter, J. A., Letley, D. P., Cook, K. W., et al. (2014). A role for the vacuolating cytotoxin, VacA, in colonization and Helicobacter pylori-induced metaplasia in the stomach. The Journal of Infectious Diseases, vol. 210, pp. 954-963.

[121] Neal, J. T., Peterson, T. S., Kent, M. L., et al. (2013). Pylori virulence factor CagA increases intestinal cell proliferation by Wnt pathway activation in a transgenic zebrafish model. Disease Models \& Mechanisms, vol. 6, pp. 802-810.

[122] Lu, R., Wu, S., Zhang, Y. G., et al. (2014). Enteric bacterial protein AvrA promotes colonic tumorigenesis and activates colonic beta-catenin signaling pathway. Oncogenesis, vol. 3, e105.

[123] Rhee, K. J., Wu, S., Wu, X., et al. (2009). Induction of persistent colitis by a human commensal, enterotoxigenic Bacteroides fragilis, in wild-type C57BL/6 mice. Infection and Immunity, vol. 77, pp. 1708-1718.

[124] Dabek, M., McCrae, S. I., Stevens, V. J., et al. (2008). Distribution of beta-glucosidase and beta-glucuronidase activity and of beta-glucuronidase gene gus in human colonic bacteria. FEMS Microbiology Ecology, vol., 66, pp. 487-495.

[125] DeLuca, J. A., Allred, K. F., Menon, R., et al. (2018). Bisphenol-A alters microbiota metabolites derived from aromatic amino acids and worsens disease activity during colitis. Experimental Biology and Medicine, vol. 243, pp. 864-875. 
[126] Wynendaele, E., Verbeke, F., D'Hondt, M., et al. (2015). Crosstalk between the microbiome and cancer cells by quorum sensing peptides. Peptides, vol. 64, pp. $40-48$. 